\title{
Constructing Individual Formative Itineraries for Health Impact Assessment Students
}

\author{
Anzhela Kazantseva ${ }^{1}$, Elena Kazantseva ${ }^{1}$, and Olga Kolmakova ${ }^{2 *}$ \\ ${ }^{1}$ Irkutsk State University, Pedagogical Institute, 664011, Irkutsk, Russia \\ ${ }^{2}$ Irkutsk National Research Technical University, Institute of Linguistics and Intercultural Communication, 664074, Irkutsk, \\ Russia
}

\begin{abstract}
The paper deals with some specificity problems of training differentially physically challenged students basing on the remote system of MOODLE. The authors describe the advantages of online training, represent the notion essence of "individual formative itineraries", the consideration of personal aims, possibilities and requirements necessities being included concerning every health impact assessment student. Basing on the analysis made, a technology has been developed including the following stages of individual formative itineraries constructing with the MOODLE system used in the process: diagnostic, projecting, technologic, ratable. A sequence of activities in the joint work performed by an educator and a student is described for each stage within a separate training discipline with regard to projecting an individual formative itinerary. The technology presented is oriented at achieving a higher efficiency of training physically challenged students at higher school.
\end{abstract}

\section{Introduction}

The development of an individual formative itinerary for the Health Impact Assessment (HIA) students occurs in the presence of a MOODLE remote system.

At present, basing on the Education Act of the Russian Federation (RF) the Public policy and the legal regulation of relations in regard to education are founded on a number of principles, the key one being ensuring the right to education for everybody and inadmissibility of discrimination in the sphere. This is particularly important in the context of the society being more and more comprehensive of a growing significance of a human.

In this context, it should be noted that physically challenged personalities and HIA ones have to solve their formative problems with great difficulties at the given moment. They are very likely to live in the environment, which is practically closed, and to be limited in their communication by people of the same social rank as themselves or by their close relatives. Such situation does not contribute to their formation and involvement in social life; it prevents them from selfrealization and attainment of decent standards of living and interferes with the feeling themselves to be true members of the society.

The key moment capable to change such state of things is the possibility of getting a higher education in particular, as a necessary element of socialization, professional identity formation, and determining the conditions of a successful job placement. Physically challenged personalities and HIA ones need a special formative support expressed as an exposure to a general formative environment anticipating lack of barriers and difficulties in their full rate activities including all probable forms of professional formatting [1].

What is meant here is an inclusive formation, its essence being quite well defined in the new Education Act in the RF. This Act means a formation which is oriented at "providing an equal access to a formation for all the students with due regard to the diversity of peculiar formative requirements and individual abilities". Nowadays, some real possibilities came into being due to a modern higher education diversification. They enable the solution of the problem connected with the HIA personality's individualized training in the new formative situation.

The requirements for the conditions of formation with regard to physically challenged and HIA personalities in the light of their psychological and physical development as well as their individual abilities can be found in the Federal National Standards for Higher Education, the number of indices characterizing the formation of HIA students being gradually increasing. Thus, since 2016, Schedule № HVE - 1 of "Information on the formative organization performing

* Corresponding author: olnov77@ mail.ru 
formative operations basing on higher education programs, namely, Bachelor Degree Programs, specialization programs, master's programs" has presented the information on distribution of HIA and physically challenged personalities being taught out of federal budget with regard to courses, assignment of formation and speciality occupation. In addition, data separation is anticipated with regard to physically challenged personalities rating, the ones that need special conditions for their formation being separated [2].

Nevertheless, as it is noted by B.B. Aismontas, C.B. Panyukoba, G.G. Saitgaliyeva, rather numerous matters of principle could be defined more precisely in the documents available with regard to inclusive higher education. In particular, a key problem connected with the adaptive strategy of the main professional formative program remains unsolved assuming that the students, the ones physically challenged being included, and different diseases are taken into consideration [3].

Such special formative requirements of HIA students for higher educational institutes as the use of special means of training oriented at a more differentiated "incremental" learning than the one necessary for a common student, individualization of training, development of a special and temporal organization, informative educational environment, have been highlighted by the above-mentioned authors.

In this context, it should be noted that no change in the subject matter of studies is meant but the changes, with regard to the choice of optimum forms, facilities, methodology and rates of formation or the available ways of learning that should be in the greatest compliance with individual features of students.

\section{Results}

To solve these problems, special attention should be paid to the use of e-learning facilities and remote control technologies that allow accepting and sending information in an intelligible form.

Remote programs of formation are considered by many experts to be a factor of increasing the number of physically challenged people being educated without any great financial expenses. At the same time, the data based on the higher educational establishments responses to the official queries give evidence that remote technologies, allowing HIA students to learn, are practically poorly developed. So, only $1.9 \%$ of physically challenged students learn by remote programs and $3 \%$ of them learn by special ones [2].

The presence of e-learning in the formative process gives a number of doubtless advantages, such as:

Improvement of the education quality as a result of technological innovations applying;

a higher efficiency of a formative process as a result of education expenses;

increasing volume of educational services offered without additional areas and infrastructure;

increasing the information capacity of training as a result of using alternative sources, compression and structuring of training information and shifting it into an actively functioning resource;

providing individualized training in the conditions of team teaching (the possibility of choosing an individual formative itinerary, speed, degree of complexity, operating regime that are in compliance with individual psychophysiological, intellectual and motivational specificities of a person being taught); combination of team and individual forms of training with regard to the assignments, contents and methodology to be followed;

developing communicative abilities of individuals being trained resulting from joint training, research, scientific activities in the presence of networking technologies [4].

To make the efficiency of electronic resources in the training process higher, the assignment of a course formation should be based on formative requirements of a student [by the same author].

In this context, the presence of remote technologies is a critical need for trainers working with the groups where some HIA students are available, the remote technologies enabling individual approach to each of the students.

There is a great number of remote training systems, the MOODLE system (Module Object-Oriented Dynamic Learning Environment) being focused on separately, as it enables developing an individual formative itinerary (IFI)for each of the students.

Developing individual formative itineraries for HIA students is quite important as it is a component of the inclusive education system. The results of a sociological survey carried out by G.Z. Yefimova and L.M. Volosnikova prove it [5].

Before the possibilities of MOODLE are assessed in the process of IEM (Information and Educational Materials) development, it is reasonable to give a close consideration to the definition of this notion as there is no monosemantic interpretation of it in the minds of the teaching stuff at the present time.

A comparative analysis of psychology-pedagogical surveys allows revealing a double character in the definition of IEM.

What is meant here is that some scientists give their consideration to an individual formative itinerary within a certain course unit. For example, N.G. Zvereva in her paper gives the definition of IEM as of an "optional structure of a student's formative activities showing his/her personality that is projected and controlled in cooperation with a teacher within a separate course unit basing on a complex psychological-pedagogical diagnostics" [6]. A similar notion can be found in the papers by V.V. Lorents and N.A. Labunskaya who, in turn, are outside a course unit and treat IEM as a purposeful, projectable, graded formative program which provides a student with the position of a subject that can choose, develop and realize a formative program if the teaching stuff, arrange a pedagogical support of a professional self-regulation and the realization of a personal potential of a teacher to be [7, 8]. M.L. Sokolova also holds the same point of view defining the IEM as the process of a student's acquisition of a formative program based on the preliminary educational 
experience and abilities oriented at the acquisition of formative programs [9]. It means that IEM is represented in the surveys performed by scientists both within a separate course unit and within an entire formative process.

Not so much the extent of the formative process as its individualization and personalized orientation that induce the interest of investigators to the renderings being considered. It is important to keep in mind that IEM is designed for each particular student who is appreciated as an active subject of his personal development. The individual program of development compiled by an educationist and the student in cooperation anticipates the availability of formative aims and training resources that are in correspondence with the abilities, possibilities, motivation and interests of the trainee.

The above information is treated as the basic one when formative resources are projected in the system of MOODLE.

In literature, one can come across attempts of describing LMS (Learning Management System) of the MOODLE system intended for realizing individual formative itineraries.

Thus, O.V. Sitnikova, S.A. Gorisev, O.B. Lobanenko, S.L. Reshetnikova indicate that a) the instruments forming the trajectory of training, being marked by an application of necessary limitations to formative elements in order to monitor the element fulfillment (review, study), following the level of assessment (with regard to controlling materials); b) the instruments enabling a diversity of formative information representation to be realized within an integrated electronic course, that is a trajectory forming for each group of learners of a given group is performed separately with regard to formative material presentation.

It is evident that the authors are mostly oriented at a training team which, in their opinion, can have been selected "in accordance with different levels of primary training, , performance, specialization and so on, all that eventually allows the most effective strategy of training to be realized (highly likely)" [10].

Along with this, the very definition of IEM is indicative of the personalization of the training process, that is the necessity of taking account personal aims, abilities and requirements of every student, this being a particularly important factor in the context of HIA students.

Basing on the above-mentioned, development of the technologies of individual formative itineraries must be carried out, using the MOODLE instruments that are of a special interest with regard to the projecting IEM intended for a certain HIA student.

The given technology is aimed at the production of an effective formative environment for HIA students. It is characteristic for its clear and friendly interface and efficient formative cooperation [3].

The personalization system of the training process that comes into being in the process of remote training enables the realization of a personality-oriented approach to each student. The personal approach focuses a teacher's efforts on the work preventing any problems connected with the peculiarities of a subject conditioned by the limitation of physical abilities. Due to a remote learning, a student gradually turns into a fully functioning subject of formative-cognitive activities and interpersonal communication acquiring the possibilities to direct the efforts at self-development and selfactualization.

Thus, a personal-oriented approach anticipates observing the following conditions: tracking the possibilities and formative requirements of physically challenged and HIA students, personalized character of the formative process for physically challenged and HIA students, formation of a great competition variety for physically challenged and HIA students and their socialization; development of a higher motivation for training in physically challenged and HIA students [3].

In this context, it is possible to mark the following stages of IEM compilation in the presence of the MOODLE system: diagnostic, designing, technologic, ratable.

It is reasonable to give the assignment a more detailed consideration.

The diagnostic stage is a key one as it is the results of diagnostication that are oriented at a further designing of the IEM as a whole.

At the given stage of technologies, the level of knowledge operated by a student is revealed by means of test assignments different in variants. The main problems of the testing are getting acquainted with a student, approaching the student and assessing the student's knowledge level.

Entry testing gives the most general presentation of the knowledge level being possessed by a HIA student, nevertheless a teacher can see bright personal peculiarities of a student to be, make assessment of the open-mindedness and range of interests, determines the speech advancing.

Monitoring test questions in the MOODLE system is performed in the presence of a question pool that enables not only to solve the problems of an entry control, but also of the current one or the final check, otherwise it can be used with regard to training tests. Besides, test questions can be common for some tests or be chosen incidentally from a bank of questions ensuring the possibility to individualize the testing system for HIA students.

\begin{tabular}{cc} 
A number of & \multicolumn{2}{c}{ MOODLE system } \\
properties/characteristics & can contribute
\end{tabular} individualizing a diagnostic stage: test time limitation and limitation with regard to the number of testing attempts; limited time of test assessment; predetermined order of question formulation in a test and variants of replies to the questions; test launching in different regimes ( for example, in an adaptive regime a test taker is offered an unlimited number of attempts to answer each of the test questions, prompting being anticipated and wrong replies being assessed by dement points that are to be extracted from the total balance resulting a test); variable resulting test data for test takers.

During an entry testing, it is an important task for an educator to understand what and in what way can be 
performed by a student during further remote studies. Entry testing requires that an educator possessed proper proficiency and flexibility. Diagnostics can be effective only in the circumstances when an educator is oriented both at the human abilities of a student and at his real knowledge with regard to a particular discipline.

This is the way for the diagnostics results to become the basis for projecting individual formative courses in the conditions of remote studies.

The diagnostic stage is followed by a designing one, where an educator starts developing the strategy of training.

The designing stage anticipates collaborative activities of an educator and a HIA student. At the given stage, the students get acquainted with the total program of the formative course focusing on the major topics of the discipline and planning their final formative products and the forms of their representation. They plan their work; choose means and ways of their activities selecting the forms of control and assessment.

The above-mentioned stage results in the development of the so-called individual technological card of a discipline. In the MOODLE resource, there are some obligatory topics with regard to the discipline program that are to be acquired; additional program units selected by a student for a more profound acquisition; the instruments of the program mastering are determined (a forum, chat, work with glossaries, etc.); the terms of material studies are determined (the system allows to establish a temporal interval); the control forms of the material being studied show themselves as definite thematic assignments.

The technologic stage gives way for the forthcoming program to be realized and for the students to advance sequentially with regard to individual formative itineraries.

It is meant here that studying each new portion of the formation material is preceded by an offer to read and get informed of the theoretical part aimed at studying the subject matter and basic theoretical items. The information can be acquired by means of video-lectures (for the hypo seeing) or text presentations and lectures (for the acoustically challenged).

As for preparing formative material for the lectures, it is to be divided into several stages, each one being followed by a control of the knowledge acquired.

The system is necessary to be preplanned in such a way that students could study the formative material again or get an additional information in case of wrong answers being given to the questions. If the questions are given correct answers, a student can be successfully advanced all over the stages of a lecture.

On studying the theoretical part, a student advances at the next stage, i.e. acquiring new activities, the ability of a student to the advancement being checked by means of testing assignments. Such assignments are placed after each block of lectures determining the availability of minimum necessary level of knowledge that enables students to absorb new information. As Ya.G. Martyushova indicates it, the necessity of such control is proved by the semantic theory of information developed by $\mathrm{Yu}$.A. Shreider. The theory has been known since the 1960s [11]. Having overcome an assessment test corrected by the educator personally, a student advances to practical activities, the student being allowed to consult either the theoretical material or a sample problem (that can be presented by a teacher as the block of "Explanation/Poyasneniye" at different stages of practical assignments fulfilling or once again give consideration to the ways of activities. The general view of the students' basic activities to be oriented at are constructed.

The sequence and logic characteristics for performance of some kinds of activities are analyzed by students together with the teacher, the teacher assisting the students in organizing their activities, selecting particular methods of work, giving individual consultations in order to solve appearing problems (which is anticipated in the MOODLE system by the presence of forum and chat programs and the possibility to write personal messages), correcting a preplanned itinerary

It should be emphasized that the efficiency of the training being considered depends on an educator who is good at the specificity of remote education and is able to offer an expert assistance in the process of getting and acquiring knowledge, is capable of correcting and monitoring the process of remote learning.

The activities of an educator include instructional and methodical material provision and assistance in problem solution with regard to an academic performance and mastering training material by the students in the process of formation; establishing formative environment in agreement with the conditions of training and realizing some technological support;

holding individual and team tutor's consultations for most actual problems of training and the methods of their solution to be discussed;

developing a remote course as the major constituent of an informational -training environment;

training and formative activities integration;

arranging favourable psychological conditions for training, interpersonal cooperation and backgrounds for reflexion [12].

As it was marked by V.V.Rubtsov, L.G. Vasina, L.S. Kuravskiy, V.V. Sokolov, "the activity of physically challenged student under the guidance of skilled educators having a considerable scientific and practical experience contribute to a higher efficiency of a training process, lower risks if disappointment in one's own forces, helping to get adapted in the conditions of higher schooling" [13].

To make the training more efficient at the technologic stage, methodological recommendations are necessary to be located within the resource of MOODLE. The following recommendations belong to this kind: a) recommendations on rational organization of training work (the rules of self-education, the ways of time rational planning, the forms of one's personal labour control, etc.); b) recommendations on dealing with learning information (how to work with a book, article, instructional aid, methods of dynamic reading and speed reading, ways of work with literature, methods of search for information, etc.); c) recommendations on 
work with notes (the plan of writing an essay, personal and business letters, summary, etc.) [14].

The ratable or assessment stage is aimed at objective assessment of students' achievements with regard to the planned purpose. At the given stage of an individual projected formative itinerary, the results of the total students' work are reviewed, typical mistakes and drawbacks and also successes and fails are being analyzed. The MOODLE system allows one to accumulate the results of the work performed and it also gives the possibility to review the complete amount of a trainee's activities and visually demonstrates the amount of the efforts made.

The ability to reflex is particularly significant at the given stage and it belongs to the number of capacities that are to be possessed by higher school students. The reflection or introspection helps the students interpret and master the knowledge they get, formulate the values, assess the results, determine the aims of the further work, correct the students' formative itinerary. We deal with the reflection when a person's attention is paid to him/herself and to his/her consciousness, in particular to the products of his/her own activities and repeated interpretations of some kind [15].

Interpreting at least three characteristics of activities performed by training subjects is realized through reflection; 1) practical (What has been done? What is the major result?); 2) technological (What means by? Stages, activities algorhythms', etc.); 3) world outlook (Why am I doing it? Is the result obtained in correspondence with the objective set? What are the changes occurring in my life as a result of it? What changes can happen? Etc.)

This is the way the technology presented covers the sequence of actions performed by an educator and a student in their joint work oriented at projecting an individual formative itinerary within a separate training discipline regarding its individual peculiarities [16].

Besides, in order to solve the problems and achieve the objectives of individual training successfully the training process under consideration should be first of all professionally oriented which is determined, as V.F. Poddubny means it, by a professional orientation of a student.

The professional orientation also predefines the importance of a student's self-identity in defining criteria, variants and consequences of the choice of the training strategy, the search for sources of the necessary training information [17].

\section{Conclusions}

In conclusion it should be noted that while simulating individual formative itineraries for HIA students within a higher school, the following problems are to be solved: a) theoretical and praxiological analysis regarding the problem of productive coupling forms and methodology of developing person-oriented problem training; development of a didactic learning model conditioning a higher efficiency of the learning process for HIA students at a higher school; developing the procedure of method and form choosing and also of their mutual correspondence to make the training process more efficient; experimental efficiency validation of an improved model with regard to the form productive coupling and methodology of training within developmental and personality-oriented training in high school conditions [18].

\section{References}

1. Ye.Sh. Kurbangaleyeva, D.N. Veretennikov, Psych. Sc. Ed. J. 22, 1. Pp. 169 (2017)

2. Ye.V. Arzhanykh. Psych. Sc. Ed. J. 22, 1. 150 (2017)

3. B.B. Aismontas, S.V. Panyukova, G.G.Saitgaliyeva. Psych. Sc.. Ed. J. 22, 1. 60 (2017)

4. Dvoryanchikov, T.V. Kalashnikov, L.S. Pechnikova, N.V. Frolova, Psych. Sc. Ed. J. 21, 2. 76 (2016)

5. G.Z. Yefimova, L.M. Volosnikova, Pedagogics, J., 7. Pp. 81-95 (2017)

6. N.G. Zvereva, Development of individual formative itineraries for students of a teachers training higher school based on psychologi-pedagogic diagnostics, (Master Ped. Sc. Autoref. Dis., Shuya, 2007)

7. V.V.Lorents, Developing an individual formative itinerary as a condition a prospective teacher training for professional activities, (Master Ped. Sc. Autoref. Dis., Omsk, 2001)

8. N.A. Labunskaya, Individual formative itinerary for a student: approaches to revealing the notion [Online resource]. URL: https://cyberleninka.ru/article/n/individualny $\quad \mathrm{y}$ obrazovatelnyy-marshrut-studenta-podhody-kraskrytiyu-ponyatiya (date of address: 04.02.2018)

9. M.L. Sokolova, Developing individual formative itineraries for higher school students, (Master of Ped. Sc. dis. text, 2001)

10. O.V. Sitnikova, S.A. Gorisev, O.B. Lobanenko, S.L. Reshetnikova. Technological resources of LMS MOODLE with regard to developing individual formative trajectories I st All-Russia Scient. Method. Conference of "Level specialist training: Online training and open formative resources", TPU (2014)

11. Ia.G. Martyushova, Psych. Sc. Ed. 22, 6. 45 (2017)

12. Ye.A. Chelnokova, Z.I. Tyumaseva, Vestnik, Minsk. Univer. 3/16, 10 (2016)

13. V.V. Rubtsov, L.G. Vasina, L.S. Kuravskiy, V.V. Sokolov, Psych. Sc. Ed. 22, 1. Pp, 34-49 (2017)

14. R.R. Sagitova, ECJ 2-1, 115 (2016)

15. M.V. Grigoryeva, R.M. Shamionov, N.M.Golubeva, Psych. Sc. Ed. J. 22, 5, 23 (2017) 
16. T.A. Zhdanko, T.V.Zhivokorentseva, O.F. Chuprova, Magister Dixit. 1 (13), 140 (2014)

17. V.F. Poddubniy, Vestnik Moskovskogo Universiteta

\section{MVD Rossii 5 (2009).}

18. V.D. Koldayev, Psych. Sc. Ed. J. 4, 15 (2013) 